\title{
Results of Beam Tests on a High Current EBIS Test Stand*
}

\author{
E. Beebe $\#$, J. Alessi, S. Bellavia, A. Hershcovitch, A. Kponou, R. Lockey, A. Pikin, K. Prelec, \\ Brookhaven National Laboratory, Bldg. 930, Upton, NY 11973, USA \\ G. Kuznetsov, M. Tiunov \\ Budker Institute of Nuclear Physics, 630090, Novosibirsk, Russian Federation
}

\section{Abstract}

At Brookhaven National Laboratory there is an R\&D program to design an Electron Bcam Ion Source (EBIS) for use in a compact ion injector to be developed for the relativistic heavy ion collider (RHIC). The BNL effort is directed at developing an EBIS with intensities of $3 \times 10^{9}$ particles/pulse of ions such as $\mathrm{Au}^{35+}$ and $\mathrm{U}^{45+}$, and requires an electron beam on the order of $10 \mathrm{~A}$. The construction of a test stand (EBTS) with the full electron beam power and $1 / 3$ the length of the EBIS for RHIC is nearing completion. Initial commissioning of the EBTS was made with pulsed electron beams of duration $<1 \mathrm{~ms}$ and current up to $13 \mathrm{~A}$. Details of the EBTS construction, results of the pulse tests, and preparations for DC electron beam tests are presented.

\section{INTRODUCTION}

The program at the BNL has as its objective the development of a heavy ion source of the EBIS type that would satisfy present and possible future requirements of RHIC. Implementation of such an EBIS has been discussed elsewhere, [1] and a summary of the pertinent parameters is given in Table 1. The experimental program to be completed preceding the design of the RHIC EBIS consists of 4 phases. The first phase of this program was based on experiments at the BNL TestEBIS (based on the Sandia National Laboratory's SuperEBIS), while the subsequent phases utilize an electron beam test stand (BNL EBTS) that has been constructed to serve as a proof-of-principle device for the final EBIS for RHIC. During phase 1 , an electron beam current of $1.1 \mathrm{~A}$ pulsed and $0.5 \mathrm{~A}$ d.c. has been achieved. Narrow charge state

\section{Table 1: Parameters for an EBIS meeting RHIC requirements}

\begin{tabular}{|l|c|}
\hline \multicolumn{1}{|c|}{ Parameter } & RHIC EBIS \\
\hline Electron beam current & $10 \mathrm{~A}$ \\
\hline Electron beam energy & $20 \mathrm{keV}$ \\
\hline Ion trap length & $1.5 \mathrm{~m}$ \\
\hline Trap capacity (charges) & $1.1 \times 10^{12}$ \\
\hline Yield positive charges & $5.25 \times 10^{11}$ \\
\hline${\text { Yield } \mathrm{Au}^{35+}, \text { design value }}^{\mathrm{U}}$ & $3 \times 10^{9}$ ions/pulse \\
\hline Yield $^{\mathrm{U} 5+}$, design value & $2 \times 10^{9}$ ions/pulse \\
\hline
\end{tabular}

*Work performed under the auspicies of the U.S. Department of Energy.

"Email: beebe@bnl.gov spectra of sodium (peak 7+), argon (peak 14+) and thallium (peak $41+$ ) ions have been produced, demonstrating the ability to produce sufficiently high charge to mass ratio ions of varied species. Furthermore, the heavy ion spectra of Xenon with peak charge state $\mathrm{Xe}^{27+}$ has been produced with a d.c. electron beam current above $0.4 \mathrm{~A}$ and electron beam neutralization degree above $50 \%$.[2] Encouraging results from these experiments led to the decision to proceed with phase 2 , the design, construction, and commissioning of an electron beam test stand with parameters given in table 2 .

\section{Table 2: Nominal EBTS Parameters}

\begin{tabular}{|l|c|}
\hline \multicolumn{1}{|c|}{ Parameter } & EBTS \\
\hline Electron beam current & $10 \mathrm{~A}$ \\
\hline Electron beam energy & $20 \mathrm{keV}$ \\
\hline e-beam current density & $400 \mathrm{~A} / \mathrm{cm}^{2}$ \\
\hline e-beam pulse duration & $\sim 100 \mathrm{~ms}$ \\
\hline ion trap length & $0.5 \mathrm{~m}$ \\
\hline trap capacity (charges) & $4 \times 10^{11}$ \\
\hline
\end{tabular}

This test stand will be used to develop technologies and study the physics aspects of a high intensity EBIS. This phase has been completed with the propagation of a 13 A, $50 \mu \mathrm{s}$ pulsed electron beam, more than an order of magnitude improvement over the TestEBIS beams. Phase 3 will continue with high current electron beam formation and launching studies for long pulses and d.c. beams. Assembly is nearing completion and tests will begin this Spring. The fourth phase will concern extraction of ions, the main goal being production of $1 / 3$ the final RHIC EBIS intensity. Also of interest is the development of primary ion injection into the trap, the study of ion formation in and loss from a high current electron beam, and the study of fast ion extraction. A successful operation of this device will be followed by the design of the full scale EBIS, together with the rest of the injector.

\section{ELECTRON BEAM TEST STAND}

As seen from tables 1 and 2, the EBTS is a full electron beam current and power prototype of the RHIC EBIS with one third the ion trap length. In an EBIS, high charge state ions are created by successive ionization by electron impact and are confined by the radial space charge of a high density electron beam.[3] The ion 
confinement time necessary to reach the charge state of interest imposes the minimum electron beam pulse duration for a given current density. There is considerable flexibility in these nominal parameters and increased performance in one parameter may lead to relaxation of another. For example, for a given magnetic field configuration, an increase in electron beam current may result in an increase in both electron beam current density and trap capacity. This reduces both the ion confinement time necessary to reach a given charge state (and hence, electron beam pulse duration) and the length of the trap region. A schematic of the electron beam test stand is given in figure 1.

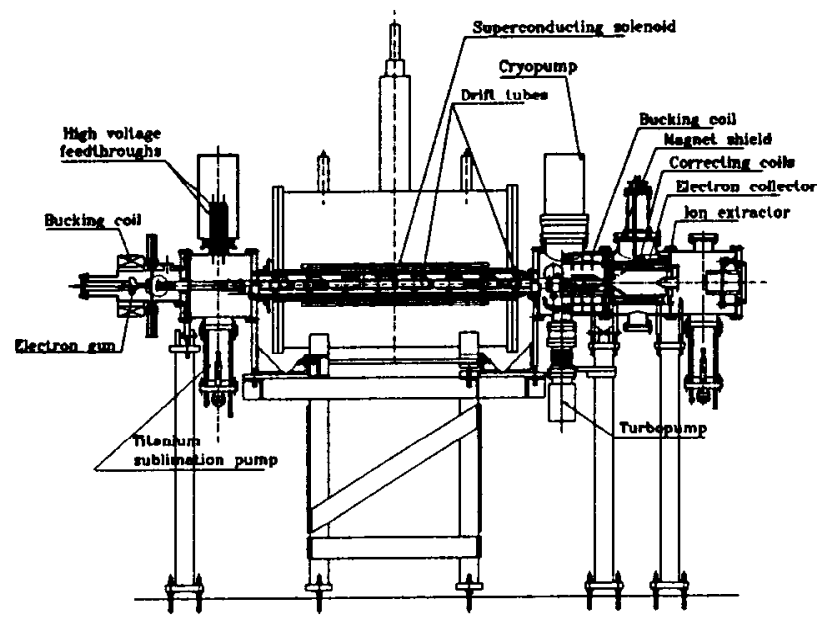

Figure 1: Layout of the electron beam test stand

Due to the low average power associated with pulsed electron beams, we were able to begin tests before all components necessary for the d.c. tests were available. Table 3 gives nominal parameters for major EBTS components. In the next section we will describe the

\section{Table 3: EBTS Components and Parameters}

\begin{tabular}{|l|c|}
\hline \multicolumn{1}{|c|}{ EBTS Item } & Parameters \\
\hline Electron Gun & $10 \mathrm{~A}, 50 \mathrm{kV} ; 8.2 \mathrm{~mm} \mathrm{LaB}$ \\
\hline Gun Solenoid & 0.2 Tesla \\
\hline Main Solenoid & 5 Tesla, 1 meter long \\
\hline Collector Solenoid & 0.05 Tesla \\
\hline Electron Collector & $50 \mathrm{~kW}$ \\
\hline Transverse Coils & 15 Gauss \\
\hline Vacuum System & $1 \times 10^{10}$ Torr \\
\hline
\end{tabular}

configuration during the pulsed electron beam tests, and note how the installation differs from the final test stand. Details of the complete test stand design and specifics concerning the electron gun and collector design have been given previously. $[4,5,6]$

\subsection{Pulsed Electron Beam Configuration}

In order to verify the basic EBTS design, pulsed electron beams of low average power were used. This allowed testing to begin before final versions of all elements of the test stand were installed. A simplified drift tube structure with two long drift tubes of $32 \mathrm{~mm}$ inner diameter in the trap region was used. A pulsed solenoid capable of producing $2 \mathrm{kG}$ fields was used with the electron gun rather than a D.C. entrance solenoid. The electron beam was collected on electrically isolated segments of an electrode assembly, figure 2 , which allowed us to measure both beam intensity and position information. The electron collector exit solenoid necessary for confining the electron beam at the source exit was not installed. As a result, some electron beam was incident on the exit aperture of the last drift tube.
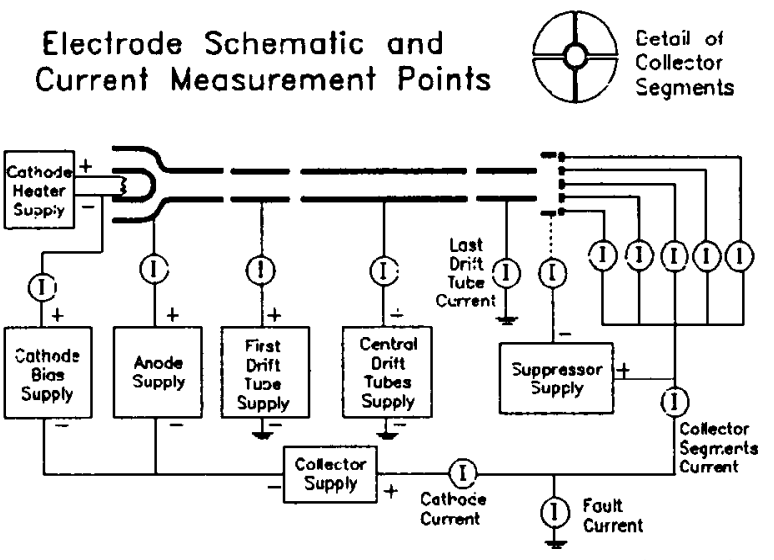

Figure 2: Electrode and current measuring schematic for pulsed electron beam tests at the BNL EBTS.

Electrically, the electrode configuration is as follows: The electron gun platform is held at approximately -10 $\mathrm{kV}$ with respect to the electron collector which is nominally held at ground through a single low impedance current measuring device. This arrangement allows us to measure sub-milliamp level current losses from the $10 \mathrm{~A}$ electron beam circuit and also avoids the expense of a $100 \mathrm{~kW}, 30 \mathrm{kV}$ isolation transformer. Drift tube supplies were referenced directly to laboratory ground and were stabilized during these tests by capacitors $\sim 20 \mathrm{nf}$ and facilitated measurement electron beam current losses on the drift tubes during the pulse.

The use of transverse coils has been important in our program and was first implemented on the TestEBIS[2], resulting in a doubling of electron beam current. The coils are especially easy to install in the case where iron shielding is not used to shape the magnetic field since the coils can reside outside the vacuum chamber. We use transverse fields of up to 15 Gauss to empirically adjust the magnetic field; thereby reducing unintentional asymmetries and introducing asymmetry at the collector where it is useful to reduce backstreaming electrons. 


\subsection{Experimental Results}

Figure 3 shows some of the earliest results using a Trek $30 \mathrm{kV}, 10 \mathrm{~mA}$ anode supply at $9 \mathrm{kV}$ to launch a $1.2 \mathrm{~A}$ electron beam. Note the $200 \mu \mathrm{s}$ slew time of the rising

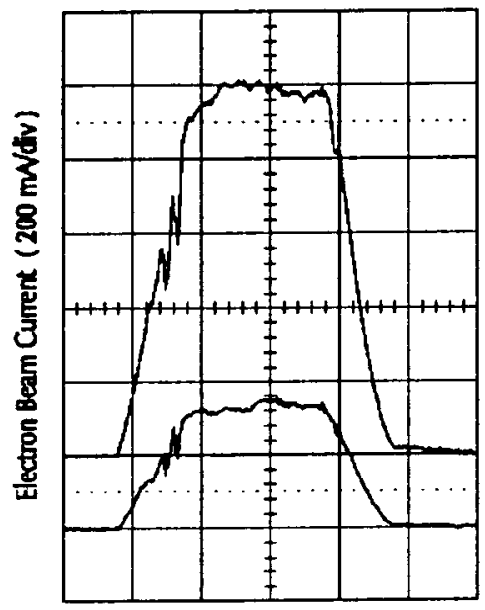

Time ( $0.2 \mathrm{~ms} / \mathrm{div})$

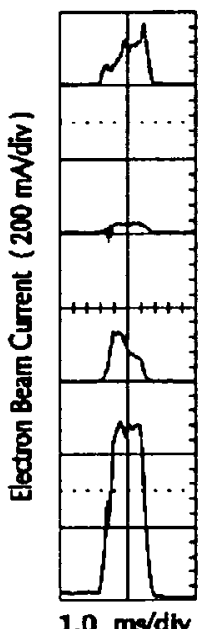

$1.0 \mathrm{ma} / \mathrm{dr}$
Figure 3: Electron beam current intercepted by various segments of the collector assembly shown in fig. 2: Sum current on 5 segments (upper left trace), central segment current (lower left trace), and 4 outer segment currents (right traces).

and falling edges. The transverse coils were adjusted to provide a rather asymmetric current distribution on the collector segments, thereby minimizing backstreaming current on the first drift tube. First drift tube losses were $30 \mathrm{~mA}$, giving a transmission factor of $97.5 \%$. (A 170 $\mathrm{mA}$ current incident on the last drift tube is included in the total collector current). The Trek anode supply was used at $30 \mathrm{kV}$ to propagate $7 \mathrm{~A}$ electron beams. In this case the slew times to and from flat top were $\sim 600 \mu \mathrm{s}$, causing considerable loading on the electrodes and giving pressures $\sim 1 \times 10^{-7} \mathrm{mBar}$ at a $0.5 \mathrm{~Hz}$ repetition rate

A fast anode supply, developed in our laboratory and based on Belke $65 \mathrm{kV}$ solid state switching modules was used during the remainder of the tests. Figure 4 shows a $13 \mathrm{~A}, 50 \mu \mathrm{s}$ electron beam pulse that was obtained with a $45 \mathrm{kV}$ anode pulse and a 5 Tesla main field. The potential difference between the cathode and trap region electrodes was $36 \mathrm{kV}$ and the entrance field was $2.4 \mathrm{kG}$. For a trap region comprised of four $15 \mathrm{~cm}$ long drift tubes, this gives an electron beam current density of $\sim 750$ $\mathrm{A} / \mathrm{cm}^{2}$ and a trap capacity of $4.3 \times 10^{11}$ charges, surpassing the objectives given in table 2 . The fast anode supply has lowered transient times to 10 us, thereby reducing beam loading. During these tests a gun region pressure of $\sim 4 \times 10^{8} \mathrm{mBar}$ was maintained at a pulse repetition rate of $2 \mathrm{~Hz}$. A transmission efficiency of greater than $99.5 \%$ was achieved and it is expected that introduction of the $50 \mathrm{~kW}$ electron collector will further reduce the losses.

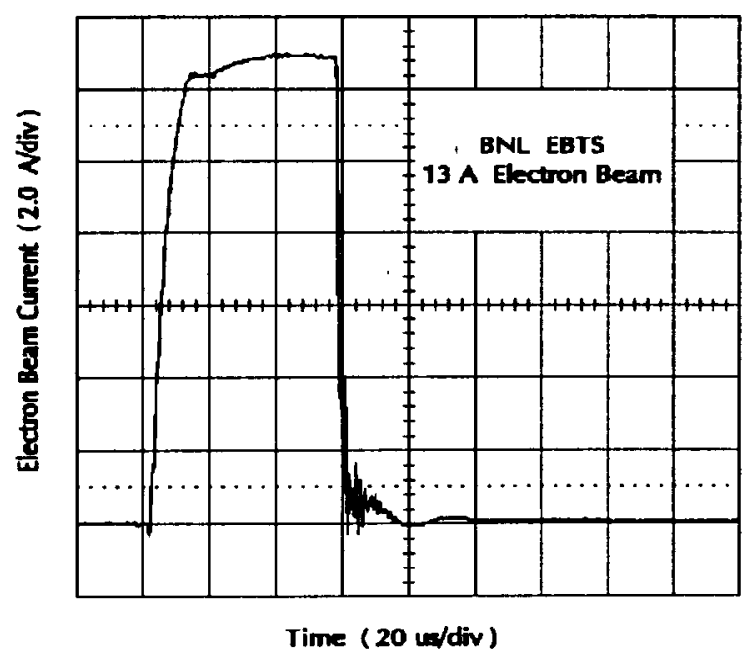

Figure 4: $13 \mathrm{~A}, 50 \mu \mathrm{s}$ electron beam pulse at the EBTS

\section{SUMMARY}

The Electron Beam Test Stand has been operated successfully with pulsed electron beams. A 13A, $50 \mu \mathrm{s}$ electron beam was transmitted. This is more than a factor of 10 increase over electron beams produced on the TestEBIS used previously. Electron beam current density, total current, and trap capacity requirements were exceeded. Final assembly is underway for long pulses and DC electron beam operation. The source will be tested for continuous and high duty factor electron beams with current $10 \mathrm{~A}$ and pulse duration at least $100 \mathrm{~ms}$.

\section{ACKNOWLEDGMENT}

We would like to thank David Boeje, Walter Hensel, Bob Horton, Tim Lehn, Dan McCafferty, Wally Shaffer, Paul Stein, and Werner Tramm for their ongoing assistance on this project.

\section{REFERENCES}

[1] H. Haseroth and K. Prelec "Possible Application of an EBIS in Preinjectors for Large Heavy Ion Colliders", Physica Scripta T71, 23 (1997).

[2] E. Beebe, J. Alessi, A. Hershcovitch, A. Kponou, A. Pikin, K. Prelec, P. Stein, and R.W. Schmeider, "Experimental Results from the Brookhaven National Laboratory Test Electron beam Ion Source", Rev. Sci. Instrum. 69, 640 (1998).

[3] E.D. Donets in "The Physics and Technology of Ion Sources", edited by I.G. Brown (Wiley, New York 1989), Chap.12.

[4] A. Pikin, J. Alessi, E. Beebe, A. Kponou, K. Prelec, and L. Snydstrup, "Brookhaven National Laboratory Electron Beam Test Stand", Rev. Sci. Instrum. 69, 697 (1998).

[5] J. Alessi, E. Beebe, A. Hershcovitch, A. Kponou, A. Pikin, K. Prelec, L. Snydstrup, and G. Kuznetsov, "Design and Initial Results of a High Current EBIS Test Stand", EPAC'98, Stockholm, (1998)

[6] A. Kponou, E. Beebe, A. Pikin, G. Kuznetsov, M. Batazova, and M. Tiunov "Simulation of 10A Electron Beam Formation and Collection for a High Current Electron Beam Ion Source", Rev. Sci. Instrum. 69, 1120 (1998). 